\title{
BACK PAIN IN POLISH MILITARY HELICOPTER PILOTS
}

\section{ALEKSANDRA TRUSZCZYŃSKA ${ }^{1,2}$, RAFAŁ LEWKOWICZ ${ }^{3}$, OLAF TRUSZCZYŃSKI ${ }^{4}$, KAZIMIERZ RĄPAŁA ${ }^{1,2}$, and MIECZYSŁAW WOJTKOWIAK ${ }^{5}$}

${ }^{1}$ Academy of Physical Education, Warszawa, Poland

Faculty of Physical Education and Sports in Biała Podlaska, Physiotherapy Department

${ }^{2}$ Professor Adam Gruca Public Hospital, Otwock, Poland

Spine Surgery Department

${ }^{3}$ Military Institute of Aviation Medicine, Warszawa, Poland

Department of Aeromedical Training

${ }^{4}$ Military Institute of Aviation Medicine, Warszawa, Poland

Department of Flight Safety

${ }^{5}$ Military Institute of Aviation Medicine, Warszawa, Poland

Department of Aviation Physiology

\begin{abstract}
Objectives: Low back pain in pilots of military helicopters is widely discussed in the world literature. Vibrations and improper seat configuration cause that cervical, thoracic and lumbar spine might be exposed to overloading. The aim of the study was to determine the incidence and intensity of pain in the spine as well as to identify subjective risk factors of back pain and its effect on the pilot's actions while flying a helicopter. Materials and Methods: 112 pilots, aged 25-56 years (mean age: $34.8 \pm 6.3$ years), actively flying helicopters, participated in the questionnaire survey. The questionnaire containing five groups of questions, elaborated by the authors, was used. Results: $70 \%$ of the pilots reported pain complaints. Pain was localized in different parts of the spine. Uncomfortable body posture during prolonged flights resulting from the lack of lumbar support exerted the highest effect on pain provocation. Conclusions: This questionnaire survey enabled to determine the prevalence of pain, its type and intensity. Knowledge on low back pain imposes the necessity to eliminate the negative environmental effect on helicopter pilotage. Elimination of risk factors is possible through appropriate physical exercises and adjustment of pilots' seats. The authors plan to conduct - in the future - detailed annual examinations among pilots with back pain and, based on the results, to elaborate a prophylactic program containing simple forms of isometric and isotonic training involving paravertebral and deep abdominal muscles designed specifically for pilots of military helicopters.
\end{abstract}

Key words:

Cervical pain, Back pain, Risk factors, Concentration disturbance, Helicopter pilots

\section{INTRODUCTION}

In the world literature, there are numerous articles describing pain in different segments of the spine in pilots of military helicopters [1-5]. The most frequently affected is low back, and the pain tends to increase with the duration of a flight. This pain may be caused by: vibrations, contact of the body with a vibrating seat and control system elements, lack of an adequate seat shock absorption system and long-lasting forced asymmetrical body position [6]. It is worth reminding that low back pain is a very common ailment not only in pilots. Low back pain is a poorly defined term, but it represents the symptoms of discomfort

Received: November 15, 2011. Accepted: March 13, 2012.

Address reprint request to A. Truszczyńska, Faculty of Physical Education and Sports, Academy of Physical Education, Akademicka 2, 21-500 Biała Podlaska, Poland (e-mail: aleksandra.rapala@wp.pl). 
and pain felt in the area of the back and buttocks. In the USA, low back pain affects about 30 million people and the cost of the treatment is about 8 billion US dollars [9]. Studies on low back pain were also conducted by Polish authors. Mazurek et al. [7] described pain in the thoraciclumbar segment of the spine, intensifying with age, in helicopter pilots. Similar results were reported by Rapała [8]. The obtained results indicated that a forced flexed position during the flight, the number of flown hours and age were the main causes of back pain. However, in the Polish literature, there is no detailed analysis of back pain in the pilots of military helicopters.

Using an opportunity resulting from the participation of a group of pilots in a specialist training in the Military Institute of Aviation Medicine, the authors carried out a questionnaire survey concerning the prevalence of pain while flying various types of military helicopters.

\section{OBJECTIVES}

The aim of the study was to determine the prevalence and degree of pain intensity in various levels of the spine as well as to identify the pain subjective risk factors and an effect on pilotage actions while flying military helicopters.

\section{MATERIALS AND METHODS}

This questionnaire survey was participated by 112 active pilots of military helicopters, aged 25-56 years (mean age: $34.8 \pm 6.3$ years), Body Mass Index (BMI) from 21.39 to 34.15 (mean: $26.38 \pm 2.58$ ). All pilots mostly flew as the first pilot. After obtaining the participants' informed consent and the approval of the Ethical Commission of MIAM, the questionnaire survey was commenced.

The questionnaire used contained 5 groups of questions:

1. Anthropometric data and the degree of loading with flights (total and annual).
2. Pain localization and intensity (in VAS scale).

3. Subjective causes of pain.

4. Effect of pain on flying a helicopter.

5. Application of prophylactic or therapeutic exercises.

\section{RESULTS}

Based on the obtained results, the authors divided the pilots into 2 groups.

1. Group 1: 88 pilots, aged between 25 and 56 years (mean age: $35.6 \pm 6.6$ years), complaining of back pain. BMI in this group was within 21.9-34.15 (mean: 26.48 \pm 2.58 ).

2. Group 2: 24 pilots, aged between 25-40 years (mean age: $31.9 \pm 3.8$ years), who did not report back pain. BMI in this group was 21.45-30.9 (mean: 26.03 \pm 2.59 ). The analyzed groups differed statistically significantly with the age at $p=0.010386$. The group of pilots complaining of back pain was older (mean 35.6) than the group without such pain (mean: 31.9 years).

There was also a statistically significant difference regarding BMI. In both groups, the pilots were slightly overweight (26.48 and 26.03). Although there is no statistical difference between the groups, this information should be taken into account when prophylactic training is created. Overweight is a risk factor for lumbar stenosis.

The obtained results were analyzed statistically with the non-parametric Mann-Whitney test, bearing in mind the following parameters: the number of hours flown annually, the total number of the flown hours, and the pilot's age. It was found that in the case of pilots suffering from back pain, the number of the flown hours was statistically higher - over 1000 hours, in comparison with the pilots without back pain.

Their total number of the flown hours was 712 hours on average. No statistically significant differences were seen in the number of the hours flown annually. The details of the analysis are shown in Table 1. 
Table 1. Effect of selected factors on back pain development

\begin{tabular}{lrrrr}
\hline \multirow{2}{*}{ Analyzed parameters } & \multicolumn{2}{c}{ Group 1 } & \multicolumn{2}{c}{ Group 2 } \\
\cline { 2 - 5 } & \multicolumn{1}{c}{$x$} & \multicolumn{1}{c}{ SD } & \multicolumn{1}{c}{$x$} & \multicolumn{1}{c}{ SD } \\
\hline Annual flown hours (n) & 104.30 & 79.50 & 90.00 & 70.70 \\
Total flown hours (n) & $1053.40^{*}$ & 699.40 & 712.60 & 510.60 \\
Age of pilot (years) & $35.60^{*}$ & 6.60 & 31.90 & 3.80 \\
Body Mass Index & 26.48 & 2.58 & 26.03 & 2.59 \\
\hline
\end{tabular}

* Differences statistically significant at $\mathrm{p}<0.05$;

$x$ - mean value in the group; $\mathrm{SD}$ - standard deviation.

The pilot flew the following helicopters: Mi-2: 29 pilots; Mi-8: 30 pilots; Mi-24: 10 pilots; W-3W: 27 pilots, and SW-4: 16 pilots. No statistically significant differences were found between the groups as for the type of the aircraft.

The results for Group 1, i.e. the pilots suffering from back pain, were additionally analyzed (see Table 2 ). The highest percentage (92\%) of the pilots complained of low back pain, while $36 \%$ - of thoracic spine pain.

The most frequent cause of pain was uncomfortable posture during prolonged flights. A pilot's posture is moderately flexed in the lumbar spine (due to seat configuration). Thoracic spine is rotated to the right because of the location of the power control column. Additionally, a pilot's head is protruded in order to observe the ground as well as steer and manage the devices.

Pilots, according to the labor law provisions, should have at maximum 6 flight hours daily. Occasionally, during a weather disaster (e.g. a flood) or rescue actions, the working time might be significantly exceeded. Intensive flights happen during real combat flights. During these extreme situations, $42 \%$ and $22 \%$ of pilots, respectively, reported pain (see Table 2).

The effect of pain on the piloting effectiveness was also analyzed (see Table 3). Nearly half of the analyzed Polish military pilots reported that pain reduced their attention concentration and influenced negatively the flight performance. Severe pain can destroy flight readiness, mild back pain can be distracting, and minimal pain can contribute to a pilot's psychological discomfort while flying.
Table 2. Localization, intensity, prevalence, duration, and cause of back pain reported by the pilots in the group with back pain $(\mathrm{N}=88)$

\begin{tabular}{|c|c|}
\hline Analyzed parameters & $\begin{array}{l}\text { Pilots } \\
(\%)\end{array}$ \\
\hline \multicolumn{2}{|l|}{ Localization of back pain } \\
\hline cervical spine & 52 \\
\hline thoracic spine & $36^{* *}$ \\
\hline lumbar spine & $92^{* *}$ \\
\hline \multicolumn{2}{|l|}{ Pain intensity in VAS scale } \\
\hline from 1 to 5 & 68 \\
\hline from 6 to 10 & 32 \\
\hline \multicolumn{2}{|l|}{ Prevalence } \\
\hline $\begin{array}{l}\text { rarely (at least once a month, but less than once } \\
\text { a week) }\end{array}$ & 75 \\
\hline frequently (at least once a week) & 25 \\
\hline \multicolumn{2}{|l|}{ Pain onset } \\
\hline during the flight & 77 \\
\hline directly after the flight & 23 \\
\hline \multicolumn{2}{|l|}{ Cause of back pain } \\
\hline vibration & 34 \\
\hline uncomfortable posture & $83^{* *}$ \\
\hline $\begin{array}{l}\text { prolonged flights (in rescue actions, weather } \\
\text { disasters) }\end{array}$ & $42^{*}$ \\
\hline intensive (combat) flights & 22 \\
\hline head loading & 31 \\
\hline
\end{tabular}

* Statistically significant differences in relation to the annual number of the flown hours at $\mathrm{p}<0.05$.

** Statistically significant differences in relation to the total number of the flown hours at $\mathrm{p}<0.05$.

Table 3. Effect of back pain on task performance during the flight

\begin{tabular}{lc}
\hline \multicolumn{1}{c}{ Type of activity } & $\begin{array}{c}\text { Pilots } \\
(\%)\end{array}$ \\
\hline Impediment of circular observation & 13 \\
Impediment of flying the helicopter & 23 \\
Reduced concentration & 48 \\
No effect on flight activities & 16 \\
\hline
\end{tabular}


Table 4. Prophylactic activities of pilots with back pain

\begin{tabular}{lc}
\hline \multicolumn{1}{c}{ Type of exercises } & $\begin{array}{c}\text { Pilots } \\
(\%)\end{array}$ \\
\hline Strengthening-stabilizing exercises & 50 \\
Stretching & 31 \\
Enhancing physical fitness & $55^{*}$ \\
Specialist, individual exercises under & 5 \\
$\quad$ a physiotherapist's supervision & \\
Physiotherapy & 7 \\
\hline
\end{tabular}

* Statistically significant differences in relation to the annual number of the flown hours at $\mathrm{p}<0.05(\mathrm{p}=0.02091)$.

This questionnaire survey aimed also at discovering what precautionary activities the pilots undertake to prevent back and neck pain, such as practicing various prophylactic physical exercises (see Table 4). Only 50\% of the surveyed pilots with back pain and $50 \%$ of the surveyed pilots without back pain practiced spine strengthening-stabilizing or endurance physical fitness exercises. It is very alarming that only $5 \%$ of the pilots with back pain in this group took advantage of professional physiotherapeutic assistance.

\section{DISCUSSION}

It seems that in the military rotary wing aviation the threshold number of the flown hours producing back pain is 1000 hours, and the threshold pilot's age is 35 years. This data corresponds to the peak of morbidity in the general population being $35-55$ years.

The subjective risk factors for the onset of back pain were uncomfortable posture during a flight and prolonged flights. The pilot's seat in the helicopter made comfortable posture impossible and no possibility to change it additionally induced the onset of pain. Prolonged flexed body posture may produce postural pain or discogenic pain. Pilots have no possibility to change their posture until the flight has ended.

Cunningham et al. [10] investigated the prevalence of back pain. They surveyed experienced RAF pilots with high numbers of the flown hours who were flying various types of helicopters. The majority of respondents (83\%) suffered from low back pain. The pain persisted during everyday activities in $68 \%$ of the examined RAF pilots. In the opinion of these authors, the pain most frequently affected the lumbar segment of the spine and intensified accordingly to the duration of flights.

The prevalence of back pain was also analyzed by Mohler [11] who surveyed 131 Australian military helicopters pilots. In reply to 69 questions, $16 \%$ of the respondents reported regular low back pain. Twenty-eight percent described it as discomforting, and 39\% of respondents suffered from low back pain occasionally.

The researchers from the Military Institute of Aviation Medicine dealt with back pain already at the end of the eighties. The studies carried out by Falkowski [12] aimed at evaluating X-ray pathologies in the osteoarticular system in 34 pilots exposed to vibrations while flying an Mi-2 helicopter. Radiological results of these studies have shown that the frequency and amplitude of the vibrations in the helicopter of this type, ranging from $2 \mathrm{~Hz}$ to $20 \mathrm{~Hz}$, did not produce marked changes in the osteoarticular system. The above is confirmed by our results. Despite the fact that pilots subjectively relatively often indicated vibrations as the factor causing back pain (34\%), this factor was statistically insignificant. Other risk factors such as intensive flights or helmet weight were also insignificant.

Similar studies were carried out by other Polish authors from the Military Institute of Aviation Medicine, e.g. Bembnowski and Miszczak [13] who examined pilots radiologically and showed that characteristic symptoms in these pilots who complained of back pain were a decrease in the physiological lordosis, increased neck muscles tone and limited spine mobility indicating impaired functioning of the ligamentous and muscular structures.

Researchers in several armies have tried to solve the problem of back pain during the flight. In RAF [10], lumbar spine support has been fitted for each pilot. This way, the 
comfort of the body during the flight has been improved in the supported sitting position, which has led to reducing the lumbar spine pain.

The support of the lumbar spine enables proper spine positioning and maintains physiological lordosis without increasing muscular tone. Stevanović and Jovelić [14], summing up their studies, recommend spine support. This conclusion results from the outcome of the muscular activity registered with surface EMG. Lopez-Lopez et al. [15] observed the variable tone of the sacrospinal muscles during manual helicopter piloting caused by asymmetrical posture (bent and rotated to the right). This posture exerts unfavorable effect on the nucleus pulposus positioning within annulus fibrosus, making it move backwards and aside. This predisposes to annulus fibrosus damage and back pain.

The concentration disturbances in our results were similar to those noted in the studies of Tomea et al. [16], but what is rarely mentioned, some of the articles underline that over $90 \%$ of pilots suffer back and neck pain. It means that in extreme cases pilots have to be grounded and go into surgery. An unknown number of pilots may continue the flight despite their adverse physical and psychological condition. Generally speaking, any form of back pain can influence a pilot's situational awareness (defined as an internalized mental model of the current state of the flight environment) and decrease the flight safety. It is obvious that any kind of stressor (also back pain) affects situational awareness, including attentional narrowing, reduction in information intake and in working memory capacity. This potentially leads to mistakes or adversely impacts tactical and strategical goals. All of these items are closely connected with concentration impairment. It is worth stressing that in our study no respondent discontinued the flight, landed earlier or refused to fly, due to the experienced ailment.

Tomae et al. [16], based on the results of their studies, concluded that a pilot's seat needs to be reconstructed and special rehabilitation programs should be introduced as back pain in pilots caused: concentration disturbances in $55 \%$ of the study subjects, earlier mission termination in $16 \%$, and $7 \%$ of the examined pilots refused to continue the flight. In the Polish rotary wing aviation, interference with their concentration was reported by $48 \%$ of the examined pilots in comparison with $55 \%$ in the Australian studies.

Lis et al. [17] also observed a dependence of back pain and ischialgia on the sitting position lasting many hours as well as sitting in asymmetrical posture and additional harmful effect of vibrations on the pilots. The authors investigating the effects of vibrations came to controversial conclusions. De Oliviera et al. [18] examined 12 helicopter pilots during 2-hour flights. Using EMG, the fatigue of sacrospinal muscles was recorded. No statistically significant changes were noted. The authors concluded that vibrations did not cause back pain.

Bridger et al. [19] carried out the studies including 246 RAF pilots in Great Britain, analyzing in detail the tasks performed in the cabin. They found that $80 \%$ of these pilots suffered from back pain. The most frequently (in 72\%) back pain affected the pilots flying in bad weather, basing exclusively on dash-board readings. The second pilots and instructors suffered from back pain less frequently $(24 \%)$. The pilots were convinced that back pain did not result from vibrations.

Similar conclusions were drawn by Norwegian researchers Hansen et al. [3]. They stated that low back pain in helicopter pilots during a flight concerned $50.5 \%$ of the examined pilots, whereas back pain during military missions $49.3 \%$. The pilots complained of back pain 6 times more often than other crew members. Nearly half of the pilots (48.6\%) were convinced that pain reduces the quality of their work and affects the flight safety. The prevalence of back pain depended on the total number of flown hours.

Helicopter pilots are exposed to factors unfavorable from the ergonomic point of view. This is confirmed by the studies 
of Balasubramanian et al. [20]. The analysis of EMG scans of 20 helicopter pilots made during the flight showed that there is a statistically significant relationship between the muscles fatigue (the right lumbar quadrate muscles) and duration of the flight. It also related to the total number of the flown hours and pain occurrence. Muscular fatigue weakly correlated with BMI and a pilot's age.

Interesting and surprising is the result of our studies showing that over $30 \%$ of the respondents suffer from thoracic spine pain. In the general population, the pain in this segment of the spine was noted in $2 \%$ of individuals only. It is most probably associated with the forced position, when the pilots observe dash-board readings. Our results confirm those obtained by other authors. For instance, interesting results were reported by Israeli researches Landau et al. [21], who analyzed MRI scans in pilots of different aircrafts. They found that 10 out of 13 helicopter pilots suffer from discogenic upper lumbar pain at the level of L1-L4. It should be stressed that in the general population, the pain at this level is noted rather rarely. Gander et al. [22] found that a prolonged working day increased the back pain prevalence by 12 times. In our studies, the prevalence of neck pain was similar to that seen in the Danish aviation research. According to Marieke et al. [23], neck pain was found in $43 \%$ of the examined pilots and only $20 \%$ of them reported regular occurrence of such pain during each flight.

The authors plan to conduct, in the future, detailed annual examinations among pilots with back pain and - based on the results - to elaborate a prophylactic program containing simple forms of isometric and isotonic training involving paravertebral muscles, designed specifically for the pilots of military helicopters.

\section{CONCLUSIONS}

1. Our questionnaire survey provided information on the scale and type of pain in the spine in military helicopter pilots.
2. Determination of the causes facilitates finding the way to eliminate an effect of unfavorable environment on piloting helicopters.

3. The relationship between back pain and the number of the flown hours was shown.

4. The number of pilots knowing the nature of back pain and undertaking precautionary activities is insufficient. The authors plan to conduct, in the future, detailed annual examinations among pilots with back pain and - based on the results - to elaborate a prophylactic program containing simple forms of isometric and isotonic training, involving paravertebral muscles and deep abdominal muscles, designed specifically for the pilots of military helicopters.

\section{REFERENCES}

1. Bowden T. Back pain in helicopter aircrew. A literature review. Aviat Space Environ Med 1987;5:461-7.

2. Froom P, Barzilay J, Caine Y, Margaliot S, Forecast D, Gross M. Low back pain in pilots. Aviat Space Environ Med 1986;57:694-5.

3. Hansen B, Wagstaff AS. Low back pain in Norwegian helicopter aircrew. Aviat Space Environ Med 2001;72:161-4.

4. Shanahan DF, Reading TE. Helicopter pilot back pain: A preliminary study. Aviat Space Environ Med 1984;55:117-21.

5. Sheard SC, Pentybridge RJ, Wright JM, McMillan G.H. Back pain in aircrew. An Initial Survey. Aviat Space Environ Med 1996;67:474-7.

6. Delahaye RP. Physiopathology and pathology of spinal injuries in Aerospace medicine. AGARD 1982;250:261-308.

7. Mazurek K, Kozicki T. Selected problems spine pain in military pilots. Probl Med Lot 2001;2(5):47-54 [in Polish].

8. Rąpała A. Problems of back pain in military pilots. Pol Przegl Med Lot 2005;12(2):145-51 [in Polish].

9. Deyo RA, Tsuiwu YJ. Descriptive epidemiology of lowback-pain and its related medical-care in the United States. Spine 1987;12:264-68. 
10. Cunningham K, Ocherty S, Tyler AW. Prevalence of low back pain $(L B P)$ in rotary wing aviation pilots. Aviat Space Environ Med 2010;81:774-8.

11. Mohler SR. Lower back pain is a common complaint, but precautionary practices help pilots cope. Hum Factors Aviat Med 2000;47(3):1-6.

12. Falkowski J. Examination MRI of vibration influence on osteoarticular system in helicopter pilots. Med Lot 1989;99: 18-21 [in Polish].

13. Bembnowski B, Miszczak J. Spine pain in pilots. Med Lotn 1989;02:48-55 [in Polish].

14. Stevanović S, Jovelić S. Usefulness of the lumbar support cushion for pilots of military helicopters. Vojnosanit Pregl 2000;57(6):657-63.

15. Lopez-Lopez JA, Vallejo P, Rios-Tejada F, et al. Determination of lumbar muscular activity in helicopter pilots: A new approach. Aviat Space Environ Med 2001;72:38-43.

16. Thomae MK, Porteous JE, Brock JR, Allen GD, Heller RF. Back pain in Australian military helicopter pilots: a preliminary study. Aviat Space Environ Med 1998;69(5): $468-73$.
17. Lis AM, Black KM, Korn H, Nordin M. Association between sitting and occupational LBP. Eur Spine J 2007;16(2):283-98.

18. De Oliveira CG, Nadal J. Back muscle EMG of helicopter pilots in flight: effects of fatigue, vibration, and posture. Aviat Space Environ Med 2004;75:317-22.

19. Bridger RS, Groom MR, Jones H, Pethybridge RJ, Pullinger N. Task and postural factors are related to back pain in helicopter pilots. Aviat Space Environ Med 2002;73(8):805-11.

20. Balasubramanian V, Dutt A, Rai S. Analysis of muscle fatigue in helicopter pilots. Appl Ergon 2011;42(6):913-8.

21. Landau DA, Chapnick L, Yoffe N, Azaria B, Goldstein L, Atar E. Cervical and lumbar MRI findings in aviators as a function of aircraft type. Aviat Space Environ Med 2006;77(11):1158-61.

22. Gander PH, Barnes RM, Gregory KB, Graeber RC, Connell LJ, Rosekind MR. Flight crew fatigue III: North Sea helicopter air transport operations. Aviat Space Environ Med 1998;69(9 Suppl):B16-25.

23. Van den Oord MH, De Loose V, Meeuwsen T, Sluiter JK, Frings-Dresen MH. Neck Pain in Military Helicopter Pilots: Prevalence and Associated Factors. Mil Med 2010;175:1-55.

This work is available in Open Access model and licensed under a Creative Commons Attribution-NonCommercial 3.0 Poland License - http://creativecommons.org/ licenses/by-nc/3.0/pl/deed.en. 